\title{
SufA - a novel subtilisin-like serine proteinase of Finegoldia magna
}

\author{
Correspondence \\ Inga-Maria Frick \\ Inga-Maria.Frick@med.lu.se
}

Received 4 June 2007

Revised 12 September 2007

Accepted 12 September 2007

\author{
Christofer Karlsson, ${ }^{1}$ Marie-Louise Andersson, ${ }^{2}$ Mattias Collin, ${ }^{1}$ \\ Artur Schmidtchen, ${ }^{2}$ Lars Björck ${ }^{1}$ and Inga-Maria Frick ${ }^{1}$
}

\author{
${ }^{1}$ Division of Infection Medicine, Department of Clinical Sciences, Lund University, BMC, B14, \\ 22184 Lund, Sweden \\ 2Division of Dermatology and Venereology, Department of Clinical Sciences, Lund University, \\ BMC, B14, 22184 Lund, Sweden
}

\begin{abstract}
Finegoldia magna is an anaerobic Gram-positive bacterium and commensal, which is also associated with clinically important conditions such as skin and soft tissue infections. This study describes a novel subtilisin-like extracellular serine proteinase of $F$. magna, denoted SufA (subtilase of Finegoldia magna), which is believed to be the first subtilase described among Gram-positive anaerobic cocci. SufA is associated with the bacterial cell surface, but is also released in substantial amounts during bacterial growth. Papain was used to release SufA from the surface of $F$. magna and the enzyme was purified by ion-exchange chromatography and gel filtration. A protein band on SDS-PAGE corresponding to the dominating proteolytic activity on gelatin zymography was analysed by MS/MS. Based on the peptide sequences obtained, the sufA gene was sequenced. The gene comprises 3466 bp corresponding to a preprotein of $127 \mathrm{kDa}$. Like other members of the subtilase family, SufA contains the catalytic triad of aspartic acid, histidine and serine with surrounding conserved residues. A SufA homologue was identified in 33 of 34 investigated isolates of F. magna, as revealed by PCR and immunoprinting. The enzyme forms dimers, which are more proteolytically active than the monomeric protein. SufA was found to efficiently cleave and inactivate the antibacterial peptide LL-37 and the CXC chemokine MIG/CXCL9, indicating that the enzyme promotes F. magna survival and colonization.
\end{abstract}

\section{INTRODUCTION}

Finegoldia magna (formerly Peptostreptococcus magnus) is part of the anaerobic commensal microflora present in the mouth, the upper respiratory and gastrointestinal tracts, the female genitourinary system and in the skin. F. magna is also the most common Gram-positive anaerobic coccus isolated from clinical specimens (Murdoch, 1998). Soft tissue abscesses, wound infections, bone and joint infections, and vaginoses are the most common infections caused by F. magna (Bowler \& Davies, 1999; Hansson et al., 1995; Murdoch, 1998; Stephens et al., 2003). Due to their anaerobic nature and relatively slow growth, Gram-positive anaerobic cocci have been little studied and their potential as human pathogens is often overlooked in the clinical setting (Murdoch, 1998).

Proteolysis is believed to contribute to bacterial virulence. Several bacterial species secrete proteinases, causing matrix

Abbreviations: AMPs, antimicrobial peptides; GST, glutathione $S$ transferase; hBD-3, human $\beta$-defensin-3; HNP-1, human neutrophil protein 1; SufA, subtilase of Finegoldia magna.

The GenBank/EMBL/DDBJ accession number for the assembled nucleotide sequence reported in this paper is DQ679960. destruction and inactivation of host defence responses. Degradation of host tissues and induction of inflammation provide bacteria with nutrients (Potempa et al., 2000; Rasmussen \& Björck, 2002; Travis et al., 1995). Microbial proteinases can also inactivate important host immunedefence molecules, such as immunoglobulins (von PawelRammingen \& Björck, 2003), proteins of the complement system (Chen \& Cleary, 1990) and antimicrobial peptides (Schmidtchen et al., 2002; Sieprawska-Lupa et al., 2004; Thwaite et al., 2006). Moreover, several species of oral streptococci produce extracellular proteinases capable of degrading albumin (Lo \& Hughes, 1996), immunoglobulin A (Plaut et al., 1974) and salivary proteins (Choih et al., 1979). Many bacteria-derived proteinases cleave human kininogens, resulting in the release of kinins, potent proinflammatory peptides (Herwald et al., 1996; Imamura et al., 2005; Scott et al., 1993; for a review see Imamura et al., 2004). A streptococcal proteinase was also shown to degrade CXC chemokines, thereby blocking the clearance of bacteria from infected tissues (Hidalgo-Grass et al., 2006).

Despite the fact that F. magna is one of the most commonly isolated anaerobic cooci from clinical specimens, the 
pathogenic significance of proteolytic activity of this bacterium is largely unknown. However, the production of gelatinases and collagenases by some F. magna isolates has been reported (Harrington, 1996; Steffen \& Hentges, 1981), and F. magna strains isolated from diabetic wound infections and non-puerperal breast abscesses were reported to have collagenase, gelatinase and hippurate hydrolase activity (Krepel et al., 1992), suggesting that enzymic activity plays a role in the development of $F$. magna soft tissue infections. Moreover, F. magna supernatants were reported to inhibit fibroblast and keratinocyte proliferation and wound healing, indicating that these supernatants contain factors that contribute to the pathogenesis of chronic wounds (Stephens et al., 2003).

The present investigation was undertaken to study proteolytic activity among $F$. magna strains. The results show that $F$. magna expresses a subtilisin-like proteinase, denoted SufA (subtilase of Finegoldia magna), that degrades antibacterial peptides of the human innate immune system. The implications of this proteolytic activity for these processes in human colonization and infection are discussed.

\section{METHODS}

Bacterial strains and growth conditions. Finegoldia magna strains were isolated at Lund University Hospital, Lund, Sweden. Bacteria were grown under strict anaerobic conditions (Anaerobic Workstation, Elektrotek) in Todd-Hewitt (TH) broth (Difco) supplemented with $0.5 \%$ Tween 80 . Cultures were harvested by centrifugation at $5000 \mathrm{~g}$ for $30 \mathrm{~min}$ at $4{ }^{\circ} \mathrm{C}$. Spent culture medium was sterilized by filtration through $0.22 \mu \mathrm{m}$ membranes. The bacterial cell pellet was washed with $20 \mathrm{mM}$ Tris/ $\mathrm{HCl}, \mathrm{pH} 7.5$, and the bacterial concentration was adjusted to $10 \%\left(2 \times 10^{10} \mathrm{cells} \mathrm{ml}^{-1}\right)$.

Proteinase isolation and FPLC. F. magna strain ALB8 was treated with $0.1 \mathrm{mg}$ papain (Sigma) and $3 \mathrm{mg}$ L-cysteine (Sigma) per $1 \mathrm{ml}$ $10 \%$ bacteria in $20 \mathrm{mM} \mathrm{Tris} / \mathrm{HCl}, \mathrm{pH} 7.5$, and incubated at $37{ }^{\circ} \mathrm{C}$ for $1 \mathrm{~h}$. Papain was inactivated by adding E64 (Sigma) to a final concentration of $1 \mu \mathrm{M}$. The supernatant was collected by centrifugation at $8000 \mathrm{~g}$ and dialysed against $20 \mathrm{mM}$ Tris/ $\mathrm{HCl}, \mathrm{pH} 7.5$, and concentrated on a Centra 6 spin column (Amicon). Extracellular proteins in sterile culture medium from strain ALB8 were fractionated by sequential ammonium sulphate precipitation at $30 \%$ and $80 \%$ saturation. The precipitated proteins were collected by centrifugation at $5000 \mathrm{~g}$ for $30 \mathrm{~min}$ at $4{ }^{\circ} \mathrm{C}$, dissolved in $20 \mathrm{mM}$ Tris/ $\mathrm{HCl}, \mathrm{pH} 7.5$, and dialysed against the same buffer. The proteins from ammoniumsulphate-precipitated (30-80\%) spent culture medium or from papain-treated bacterial cells were applied to a Mono Q 5/50 GL ionexchange column (GE Healthcare) equilibrated with $20 \mathrm{mM}$ Tris/ $\mathrm{HCl}$, $\mathrm{pH}$ 7.5. Proteins were eluted with a linear gradient of $\mathrm{NaCl}(0-1 \mathrm{M})$ and collected in $0.5 \mathrm{ml}$ fractions. The enzymic activity in the fractions was analysed by gelatin zymography (see below). Fractions containing gelatinase activity $(0.28-0.40 \mathrm{M} \mathrm{NaCl})$ were combined and concentrated by centrifugation filtration (Ultra-15, Amicon), followed by separation on a Superose $1210 / 300$ GL gel filtration column (GE Healthcare) equilibrated with $0.15 \mathrm{M} \mathrm{NaCl}, 20 \mathrm{mM}$ Tris/HCl, pH 7.5.

Antibodies. The non-ambiguous residues of the internal peptide 3, EFSSWGLTPDLR (EFS12) (see Table 1) were synthesized and used for production of a custom peptide polyclonal antiserum (Innovagen). Recombinant SufA [zymogen form devoid of glutathione S-transferase (GST)] was separated by SDS-PAGE. The gel was stained with Coomassie R-250 and the band corresponding to SufA (155 kDa)

Table 1. Amino acid sequences and masses of SufA tryptic peptides obtained by tandem mass spectrometry

To confirm the MS/MS identification SufA was in silico trypsin digested. The masses of the computed peptides were compared to the masses of the 23 de novo peptides. Of the 23 de novo peptides, 17 were found to match with a mass accuracy of $0.5 \mathrm{Da}$. The sequences of the de novo peptides were compared to the matched SufA sequences. Identical amino acid residues are indicated in bold/underlined.

\begin{tabular}{|lccccc|}
\hline Peptide no. & Experimental mass & Theoretical mass & $\boldsymbol{\Delta}(\mathbf{D a})$ & Sequence position & De novo peptide sequence \\
\hline 1 & 2126.16 & 2126.35 & 0.19 & $1018: 1036$ & MTSADLLANLSLYASVDNAR \\
2 & 2004.11 & 2004.26 & 0.15 & $944: 960$ & TPGQANLVLDPTAKVTSYK \\
3 & 1737.90 & $1737.94^{*}$ & 0.04 & $536: 550$ & VDDEFSSWGLTPDLR \\
4 & 1631.85 & 1631.79 & -0.06 & $495: 508$ & VYPSVFLGNADPHK \\
6 & 1516.78 & 1516.61 & -0.16 & $735: 748$ & $\underline{\text { ANSEFTYPGTLSTK }}$ \\
7 & 1503.73 & 1503.66 & -0.07 & $902: 914$ & $\underline{\text { FEYVKPNSE-DFKG }}$ \\
9 & 1483.89 & 1483.72 & -0.17 & $643: 656$ & ANAGAGLVQVENVLK \\
10 & 1460.76 & 1460.60 & -0.17 & $999: 1010$ & $\underline{\text { EDHKYDDLLRR }}$ \\
13 & 1335.70 & 1335.47 & -0.23 & $323: 334$ & $\underline{\text { EGVSPTNEAFRK }}$ \\
15 & 1290.74 & $1290.47 \dagger$ & -0.28 & $1143: 1153$ & QDTVYNLPVLK \\
16 & 1207.60 & 1207.29 & -0.30 & $323: 333$ & $\underline{\text { EGVSPTNEAFR }}$ \\
17 & 1199.65 & 1199.47 & -0.19 & $268: 279$ & $\underline{\text { GVAPNAQLLGMK }}$ \\
18 & 1186.74 & 1186.49 & -0.25 & $879: 888$ & $\underline{\text { NLFLDPLLLK }}$ \\
19 & 1095.58 & 1095.29 & -0.29 & $704: 712$ & $\underline{\text { YLSLKDEKV }}$ \\
20 & 1073.63 & 1073.24 & -0.39 & $1085: 1093$ & $\underline{\text { LLNDKDNLK }}$ \\
21 & 1067.51 & 1067.19 & -0.32 & $867: 875$ & $\underline{\text { YDLLDKDGK }}$ \\
23 & 903.48 & 903.03 & -0.46 & $193: 200$ & $\underline{\text { LSPELESK }}$ \\
\hline
\end{tabular}

The theoretical mass was deduced considering the following modifications: ${ }^{\star}$ pyroglutamic modification when Gln was at $\mathrm{N}$ terminus; $\dagger \mathrm{C}$-terminal Ser stripped. 
was cut out and used for production of a polyclonal rabbit antiserum (Antibody AB, Sweden). For purification of anti-SufA IgG, antiserum against recombinant SufA was applied to a protein G-Sepharose column (GE Healthcare Bio-Sciences). The column was extensively washed with PBS and bound IgG was eluted with $0.1 \mathrm{M}$ glycine- $\mathrm{HCl}$, $\mathrm{pH}$ 2.0. The $\mathrm{pH}$ was raised to 7.0 with $1 \mathrm{M}$ Tris solution. Production of rabbit antibodies against a peptide of high-molecular-mass kininogen (NAT26) has been described (Frick et al., 2006).

SDS-PAGE, immunoblot and immunoprecipitation. SDS-PAGE was performed as described by Laemmli $(1970)$ using a total polyacrylamide concentration of $8 \%$ or $10 \%$, and $3.3 \%$ crosslinking. Gels were stained with Coomassie R-250 or separated proteins were transferred onto an Immobilon-P membrane (Millipore) by using the Mini Trans-Blot system (Bio-Rad). SufA was detected with EFS12-antibodies $(1: 1000)$ or with rabbit antibodies raised against recombinant SufA $(1: 1000)$. Bound antibodies were detected by using horseradish-peroxidase-conjugated goat anti-rabbit $\operatorname{IgG}$ (Bio-Rad) and Supersignal West Pico chemiluminescent substrate (Pierce). Coomassie R-250 stained bands of interest were excised from SDS-PAGE gels and sent to Swegene Proteomics Facility (Lund, Sweden) for MALDI-TOF mass spectrometry. Analysis of antibacterial peptide degradation was performed with Tris-Tricine peptide gels (Schägger \& von Jagow, 1987) using a total concentration of $16.5 \%$ polyacrylamide, and $3.3 \%$ crosslinking. SufA preparations were immunoprecipitated with polyclonal antibodies against SufA or unspecific polyclonal NAT26 antibodies and protein G-Sepharose at $4{ }^{\circ} \mathrm{C}$ for $16 \mathrm{~h}$. Following centrifugation the supernatants were removed and analysed by gelatin zymography or used for cleavage of antibacterial peptides.

Gelatin zymography. Protein samples were dissolved in nonreducing sample buffer and incubated for $5 \mathrm{~min}$ at room temperature. Proteins were separated by SDS-PAGE using $8 \%$ or $10 \%$ polyacrylamide gels containing $0.1 \%$ porcine gelatin (Bio-Rad). After electrophoresis, gels were incubated in $2.5 \%$ Triton X-100 for $30 \mathrm{~min}$, washed in $50 \mathrm{mM}$ Tris/ $\mathrm{HCl}, \mathrm{pH} 7.5,0.2 \mathrm{M} \mathrm{NaCl}$ and $5 \mathrm{mM}$ $\mathrm{CaCl}_{2}$ and then incubated for $18 \mathrm{~h}$ in the same buffer. Areas of proteolytic activity were detected by Coomassie R-250 staining of the gel (Liotta \& Stetler-Stevenson, 1990). The following proteinase inhibitors were used for blocking of proteolytic activity: transepoxysuccinyl-L-leucylamido(4-guanidino)butane (E-64), for blocking cysteine proteinases; PMSF, for blocking serine proteinases; EDTA, for blocking metalloproteinases (all from Sigma).

Mass spectrometry and peptide de novo sequencing. The protein band on SDS-PAGE above $250 \mathrm{kDa}$ (see Fig. 2b, lane 2) corresponding to the highest gelatinase activity in Mono Q fraction 21 was excised and subjected to in-gel trypsination. The peptide samples were analysed on a Qtof Ultima API (ESI-MS/MS from Waters) coupled to a CapLC (Waters). The auto-sampler injected $5 \mu 1$ sample and the peptides were trapped on a pre-column (C18, $300 \mu \mathrm{m} \times 5 \mathrm{~mm}, 5 \mu \mathrm{m}, 100 \AA$, LC-Packings), and separated on a reversed-phase analytical column (Atlantis, C18, $75 \mu \mathrm{m} \times 150 \mathrm{~mm}$, $3 \mu \mathrm{m}, 100 \AA$, Waters). The flow through the column was $200 \mathrm{nl} \mathrm{min}{ }^{-1}$. Solvent A consisted of $2 \%$ acetonitrile, $98 \%$ water with $0.1 \%$ formic acid; solvent B consisted of $90 \%$ acetonitrile, $10 \%$ water and $0.1 \%$ formic acid. The HPLC method started with $5 \% \mathrm{~B}$ for $3 \mathrm{~min}$., then progressed from 5 to $60 \% \mathrm{~B}$ in $42 \mathrm{~min}$, from 60 to $80 \% \mathrm{~B}$ in $5 \mathrm{~min}$, kept at $80 \% \mathrm{~B}$ for $25 \mathrm{~min}, 80$ to $5 \% \mathrm{~B}$ in $1 \mathrm{~min}$ and $5 \%$ B for $15 \mathrm{~min}$. Total run time $90 \mathrm{~min}$. The mass spectrometer analysis was made by Data Directed Analysis (DDA). The mass range $\mathrm{m} / \mathrm{z}$ was $400-1600$ for MS and $50-1800$ for MS/MS. Only spectra from ions with charge states 2 and 3 were acquired.

Interpretation of the tandem mass spectra using the ProteinLynx Global Server 2.2 software returned 23 peptide sequences, each with up to five interpretations of the mass/charge spectra (no distinction between the amino acids L and I due to their identical masses). The MS/MS analysis was performed by SCIBLU-Swegene Centre for Integrative Biology at Lund University, Sweden. The non-ambiguous residues of the individual peptide sequence interpretations were used for BLAST search in the NCBI non-redundant database and for subsequent construction of degenerate primers (see below).

After the cloning of sufA (see below), the MS/MS identification was confirmed. The ORF was in silico digested with trypsin in the MS-Digest program (http://prospector.ucsf.edu/prospector $/ 4.0 .8 / \mathrm{html} / \mathrm{msdigest}$. htm) with one allowed missed cleavage site and with considered modification peptide N-terminal Gln to pyroGlu and stripping of one C-terminal residue. The computed mean molecular mass of the tryptic peptides was compared to the measured mass of the de novo peptides. A difference between computed and measured masses less than $0.5 \mathrm{Da}$ was considered as a matched peptide. The amino acid sequence identity was then compared between the matched in silico tryptic peptides and the obtained sequence interpretations of the spectrum.

Cloning and DNA sequencing. Chromosomal DNA from the $F$. magna ALB8 strain was extracted using the Gentra systems DNA isolation kit and used as template for PCR. Degenerate PCR primers were designed from the $23 \mathrm{MS} / \mathrm{MS}$ peptide non-ambiguous sequences using F. magna codon usage table [Countcodon program (Nakamura et al., 2000), http://www.kazusa.or.jp/codon/countcodon.html] based on published and unpublished sequences. To reduce degeneracy, an inosine base was used in the primers when any of the four bases was required (Knoth et al., 1988).

The initial partial amplification of the sufA gene was performed with PCR using the degenerate primers originating from peptide 17 (GVAPNAGALLGMK) forward (5'-GCDCCDAAYGCDCAAHTIHTIGGHATG- $3^{\prime}$ ) and peptide 3 (EFSSWGLTPDLR) reverse $\left(5^{\prime}\right.$ TCHGGHGTIADDCCCCADSWDSWRAAYTC- $\left.3^{\prime}\right)$. The $750 \mathrm{bp}$ product designated $17 \mathrm{Fwd} / 3 \mathrm{Rev}$ was gel-purified and sequenced. To obtain the flanking downstream DNA sequence of the gene, a forward PCR primer Inv1 (5'-CAACATCACTCCAGTACATTCTG-3'), based on the $17 \mathrm{Fwd} / 3 \mathrm{Rev}$ sequence, was used together with degenerate reverse primer 8Rev (5'-GCRTCHGGRTTYTCYTTRTCYTC-3') based on MS/MS peptide 8 (YEDKENPDAFKK). The PCR generated a $1950 \mathrm{bp}$ product. The PCR product (Inv1Fwd/8Rev) was gelpurified and sequenced. Later on, the MS/MS peptide 8 was not found to match any of the SufA in silico tryptic peptides. Reverse primer binding for the Inv1Fwd/8Rev product was probably due to a sequence corresponding to the degenerate primer sequence.

To obtain the flanking upstream and downstream DNA sequence of the gene, non-specific nested suppression PCR (Lardelli, 2002) was performed. The first PCR (non-specifically primed PCR using a single primer) was performed with primer NT1 (5'-CCTTCTCTACTGTAACCTGAACC- $\left.3^{\prime}\right)$ directed upstream and primer CT1.5 (5' TTGACTTGGCAAACCTAAGC- $3^{\prime}$ ) directed downstream. Cycling conditions were as follows: denaturation $95{ }^{\circ} \mathrm{C} 30 \mathrm{~s}$, annealing $40{ }^{\circ} \mathrm{C} 1 \mathrm{~min}$ and extension $72{ }^{\circ} \mathrm{C} 2 \mathrm{~min}$, repeated 35 cycles using Taq polymerase. The amplified PCR reaction was diluted $1: 1000$ and used as template for the reamplification PCR. The extended primers in the second PCR were ENT1 (5'-CTTCTCTACTGTAACCTGAACCCATTCC-3') directed upstream and ECT1 (5'-GACTTGGCAAACCTAAGCATTTAC-3') directed downstream. Cycling conditions were as follows: denaturation $95{ }^{\circ} \mathrm{C} 30 \mathrm{~s}$, annealing $57^{\circ} \mathrm{C}$ $1 \mathrm{~min}$ and extension $72{ }^{\circ} \mathrm{C} 4 \mathrm{~min}$, repeated 35 cycles using $\mathrm{Pfu}$ polymerase. The PCRs resulted in a $1500 \mathrm{bp}$ upstream fragment (ENT1) and an $800 \mathrm{bp}$ downstream fragment (ECT1). The products were gel-purified and sequenced. BigDye terminal DNA sequencing (Applied Biosystems) was performed according to the manufacturer's protocol. The sequence fragments were assembled using Invitrogen ContigExpress software generating a 4362 bp contig. 
Recombinant expression of SufA. The regions of the sufA gene encoding the zymogen protein (amino acids 29-1154) and the mature protein (amino acids 148-1154) were produced by High Fidelity PCR (Fermentas) using F. magna ALB8 chromosomal DNA as template. For the $\mathrm{NH}_{2}$-terminal GST-tagged constructs, we designed the following PCR primers: SufA pre-forward (5'-GTAGTCGACAAACAGATAGCACTACATAT-3'), SufA mature forward (5'GTAGTCGACGAGCATCTCCAGCATTGGC-3') and SufA reverse ( $5^{\prime}$-AGCGGCCGCTTATCAACTTTGAATTACAGGTAAGT-3'). The forward primers incorporated the Sall restriction sites and the reverse included a NotI site (underlined). The reverse primer also included two stop codons, TGA and TAA, directly after the coding segment. The amplified PCR products and the expression vector pGEX-6P-1 (GE Healthcare) were digested with SalI and NotI and gel-purified. The vector and inserts were ligated with T4 DNA ligase (Fermentas) according to the manufacturer's protocol, and transformed into Escherichia coli BL21 competent cells (Novagen) for protein expression. BL21 transformants carrying the expression plasmids were grown in $2 \times \mathrm{YT}$ medium [ $1 \%$ tryptone (Difco) and $1 \%$ yeast extract (Oxoid), $0.5 \% \mathrm{NaCl}]$ until the $\mathrm{OD}_{620}$ reached 0.5 . Recombinant protein expression was induced with $0.4 \mathrm{mM}$ IPTG. After $4 \mathrm{~h}$ induction, the bacterial cells were harvested by centrifugation at $8000 \mathrm{~g}$ and lysed by sonication, according to the manufacturer's protocol. The lysates were subjected to glutathioneSepharose affinity chromatography (GE Healthcare). The GST-tag was removed with PreScission Protease (GE Healthcare).

PCR analysis of genomic DNA for identification of SufA. To analyse the presence of the sufA gene in different $F$. magna isolates, PCR template DNA was extracted using a Gentra Systems DNA isolation kit. The used PCR primers were SigSeq Fwd (5'-TTGTTTTCATTGGCATTACC- $\left.3^{\prime}\right)$, His 247 Fwd (5'-GATACCACGGAATGCACGTA-3') and Ser578 Rev (5'-GCCATTGATGTACCACTCAT-3'). PCR products were analysed by agarose $(1 \%)$ gel electrophoresis.

Cleavage of antibacterial peptides. The LL-37 peptide (LLGDFFRKSKEKIGKEFKRIVQRIKDFLRNLVPRTES) was synthesized by Innovagen. Recombinant human MIG/CXCL9 and recombinant human $\beta$-defensin 3 (hBD-3) were from Peprotech and human neutrophil protein 1 (HNP-1) was from Bachem. Generally the peptides were incubated with SufA purified from the surface or from the culture medium of the ALB8 strain and incubated on a thermal block at indicated time points.

Bactericidal assays. Stationary-phase F. magna bacteria (strain 505) were washed with $10 \mathrm{mM}$ Tris/ $\mathrm{HCl}, 5 \mathrm{mM}$ glucose, $\mathrm{pH} 7.5$, and adjusted to a concentration of $1 \%\left(2 \times 10^{6}\right.$ c.f.u. $\left.\mathrm{ml}^{-1}\right)$. Approximately $10^{5}$ c.f.u. bacteria were incubated with various concentrations of LL-37, MIG/CXCL9, hBD-3 or HNP-1 for $1 \mathrm{~h}$ under strict anaerobic conditions. In subsequent experiments, bacteria were incubated with $1 \mu \mathrm{g}$ LL-37, $2 \mu \mathrm{g}$ MIG/CXCL9 or $2 \mu \mathrm{g}$ hBD-3, pretreated with either buffer, $250 \mathrm{ng}$ SufA or $250 \mathrm{ng}$ SufA $+1 \mathrm{mM}$ PMSF at $37{ }^{\circ} \mathrm{C}$ for $3 \mathrm{~h}$ or $16 \mathrm{~h}$, and the reactions were carried out for $1 \mathrm{~h}$. Serial dilutions of the mixtures were plated on $\mathrm{TH}$ agar in duplicates and incubated for 3 days under strict anaerobic conditions. The number of c.f.u. was then counted. All dilutions were performed in $10 \mathrm{mM}$ Tris/ $\mathrm{HCl}, 5 \mathrm{mM}$ glucose, $\mathrm{pH}$ 7.5.

\section{RESULTS}

\section{Proteolytic activity of $\boldsymbol{F}$. magna}

To visualize extracellular proteolytic activity of $F$. magna, supernatants from stationary-phase cultures of various isolates were analysed by zymography, using porcine gelatin as the substrate. The zymograms demonstrated that all examined strains express gelatinase activity in the molecular mass range of $130-200 \mathrm{kDa}$ (Fig. 1a). Most strains also showed proteolytic activity above $250 \mathrm{kDa}$; the strain ALB8, previously used for isolation of the albuminbinding protein PAB (de Château \& Björck, 1994), was chosen for further analysis and proteinase identification. When grown in liquid culture, strain ALB8 reaches stationary phase at approximately $89 \mathrm{~h}$ of cultivation (Fig. 1b); growth medium from different time points was

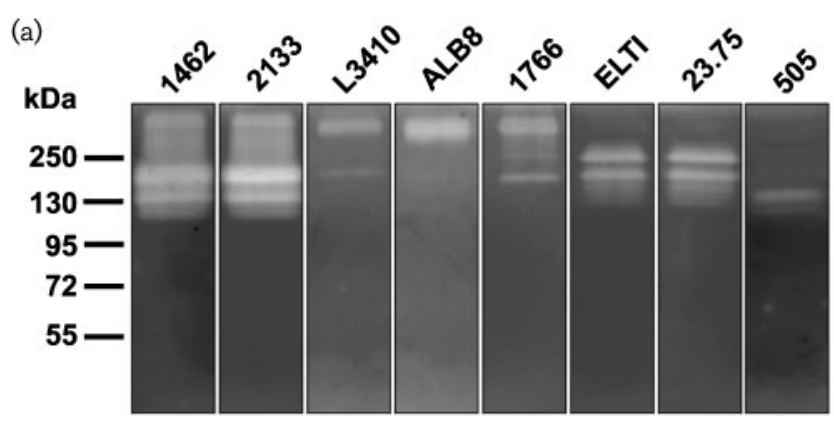

(b)

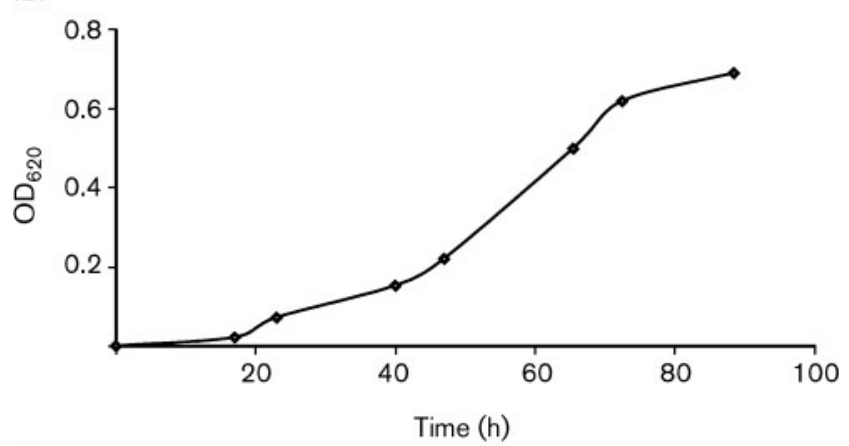

(c)

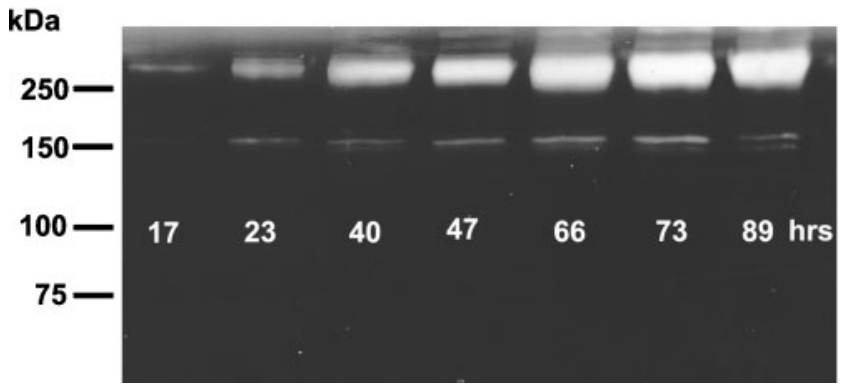

Fig. 1. Gelatinase activity of $F$. magna. Proteinase activity of $F$. magna was analysed on polyacrylamide gels containing $8 \%$ polyacrylamide and $0.1 \%$ gelatin. Proteolytically active proteins appear as clearings in the stained gel. (a) Stationary-phase bacterial supernatants $(10 \mu \mathrm{l})$ of indicated $F$. magna strains were analysed. (b) Strain ALB8 was grown under anaerobic conditions in TH medium supplemented with $0.5 \%$ Tween 80 at $37{ }^{\circ} \mathrm{C}$. (c) At indicated time points samples were collected from the growth medium in (b). Bacteria were spun down and $10 \mu \mathrm{l}$ samples of the resulting supernatants were analysed by zymography. Migration of molecular mass standards is indicated to the left. 
(a)

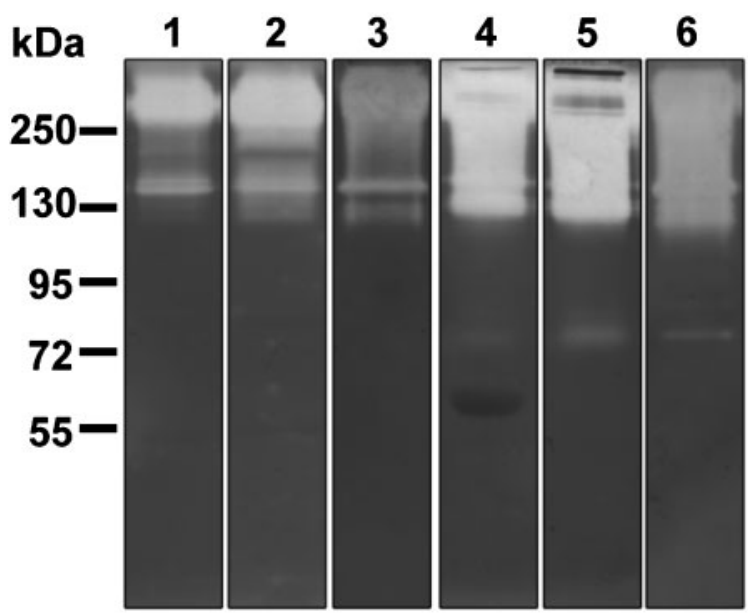

(b)

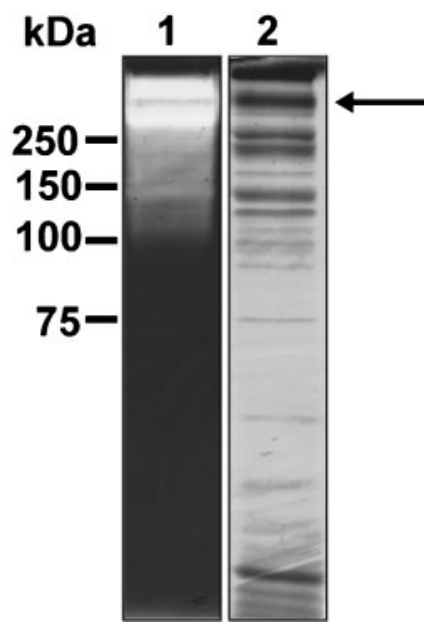

Fig. 2. Identification of a gelatinase from F. magna. (a) Gelatinase(s) purified from F. magna strain ALB8 were analysed by zymography using $8 \%$ polyacrylamide and $0.1 \%$ gelatin. Lanes $1-3$, ammonium-sulphate-precipitated spent culture medium; lanes 4-6, papain-released proteins from the bacterial surface. Lanes 1 and 4, crude protein extract; lanes 2 and 5, pooled fractions from ion-exchange chromatography; lanes 3 and 6 , pooled fractions from gel filtration. (b) Proteins eluted with $0.35 \mathrm{M}$ $\mathrm{NaCl}$ from ion-exchange chromatography of papain-released material were analysed on an $8 \%$ polyacrylamide zymogram containing $0.1 \%$ gelatin (lane 1), and by $8 \%$ SDS-PAGE under non-reducing and non-denaturing conditions (lane 2). The protein band marked with an arrow was cut out and sent for peptide de novo sequencing. Migration of molecular mass standards is indicated to the left.

analysed by zymography. Gelatinase activity could already be detected in the early growth phase $(17 \mathrm{~h})$, and the highest activity was observed when the bacteria were in stationary phase at $73 \mathrm{~h}$ and $89 \mathrm{~h}$ of cultivation (Fig. 1c).

To investigate whether gelatinase activity could also be detected on the cell surface of strain ALB8, papain was used to solubilize surface proteins from the bacteria, a procedure that has previously been used to release surface proteins from F. magna (Björck, 1988). Papain-released and secreted proteins of ALB8 displayed similar gelatinase activity, with a dominating clearing zone above $250 \mathrm{kDa}$ and a weaker zone at $140 \mathrm{kDa}$ (Fig. 2a, lanes 1 and 4). In both materials, the proteolytic activity was inhibited by PMSF but not by any other class of proteinase inhibitors (not shown), suggesting that the gelatinase(s) belong to the class of serine proteinases. The materials were individually subjected to ion-exchange chromatography followed by gel filtration. However, no further separation of the activity at $140 \mathrm{kDa}$ and the activity above $250 \mathrm{kDa}$ was obtained (Fig. 2a). Following ion-exchange chromatography, active fractions were also analysed by SDS-PAGE run under the same conditions as the zymography (non-reducing and non-heat-denaturing conditions). In the papain-solubilized material a band above $250 \mathrm{kDa}$, corresponding to the highest gelatinase activity on the zymograms, was detected. This band was cut out (Fig. 2b) and subjected to peptide de novo sequencing using tandem mass spectrometry (ESIMS/MS). The analysis generated 23 internal peptides.

\section{Gene cloning and sequence analysis}

In a BLAST search of the non-ambiguous sequences of the 23 peptides originating from the band above $250 \mathrm{kDa}$, peptides 3 and 17 (see Table 1) were found to align to catalytic domains of serine proteinases. PCR using degenerate primers based on these two peptide sequences yielded a 750 bp product (17Fwd3Rev) (see Fig. 3a, b). The translated amino acid sequence was homologous to serine proteinases of Gram-positive bacteria. The 3'-sequence was amplified using a forward inverted PCR primer, based on the obtained $750 \mathrm{bp}$ sequence, together with a degenerate reverse primer for MS/MS peptide 8, resulting in a $1950 \mathrm{bp}$ product (Inv1Fwd/8Rev). Further flanking downstream and upstream sequences were cloned using a non-specific, nested suppression PCR, yielding a 1500 bp upstream PCR product (ENT1) and a downstream $800 \mathrm{bp}$ PCR product (ECT1) (Fig. 3a). The assembled nucleotide sequence was submitted to GenBank under submission number DQ679960. Homologous sequences were not found in the published bacterial artificial chromosome-end library of F. magna ATCC 29328 (Goto et al., 2003).

The nucleotide sequence revealed a 3466 bp ORF, which translated into a sequence of 1154 amino acid residues with a putative molecular mass of $127 \mathrm{kDa}$. A BLAST search of the ORF against the NCBI non-redundant database revealed high homology to extracellular proteinases of Gram-positive bacteria. The most similar proteins were 
(a)

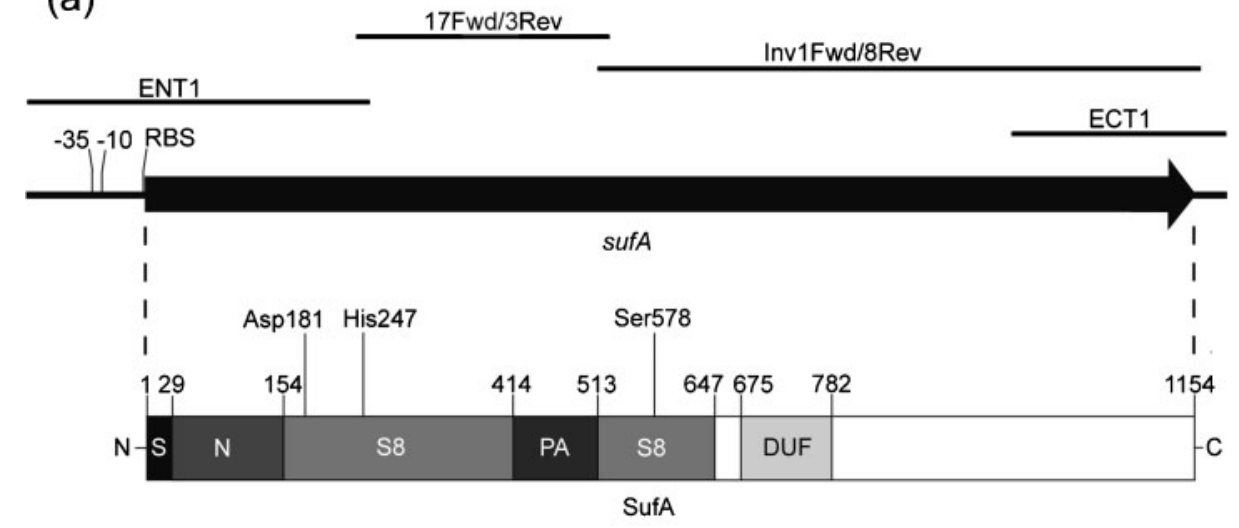

(b)

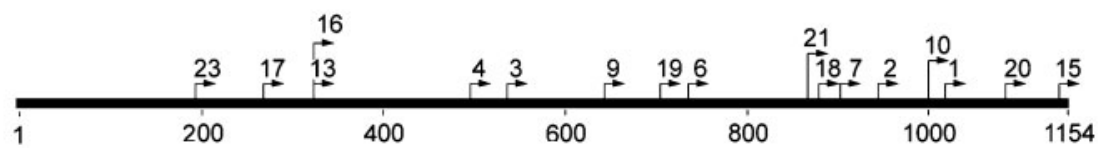

Fig. 3. Schematic representation of the SufA protein. (a) The PCR products ENT1, 17Fwd/3Rev, Inv1Fwd/8Rev and ECT1 used for sequencing are shown and their position in the sufA gene is indicated. Beginning from the $5^{\prime}$-end, the gene includes: putative -35 and -10 promoter sequences followed by a ribosome-binding sequence (RBS), and an ORF coding for SufA (1154 amino acid residues). Shown below the gene map are the putative domains found in SufA: signal peptide (S), subtilisin $\mathrm{N}$-terminal region $(\mathrm{N})$, peptidase $\mathrm{S} 8$ domain (S8), protease associated domain (PA), and domain of unknown function (DUF1034). The potential catalytic triad comprises Asp181, His247 and Ser578 (in scale). (b) 17 of the 23 de novo peptide masses matched theoretical peptide masses from in silico trypsin-digested SufA. Locations of the peptides in the ORF are indicated (in scale).

lactocepin (lactococcal cell envelope-associated proteinases) from Oceanobacillus iheyensis HTE831 (accession number NP_693854), Exiguobacterium sibiricum 255-15 (accession number ZP_00540359) and collagenolytic proteinase from Geobacillus sp. MO-1 (accession number BAF30978). The overall identity between the ORF and similar proteins was $33-34 \%$ and the homology $51-52 \%$. The regions in the ORF showing the highest degree of identity were residues $170-315$ (55-57\% identity) and $530-600$ (61-63\% identity), corresponding to regions of the catalytic domain S8 (see below and Fig. 3a).

By scanning the amino acid sequence in the MyHits (Pagni et al., 2004) and SignalP databases (Bendtsen et al., 2004), the sequence was found to include a 28 -residue signal peptide, an 89 -residue propeptide, a 595-residue peptidase S8 domain including a 99-residue protease-associated domain (PA), and a 109-residue domain of unknown function (DUF1034). The putative locations of the catalytic triad were Asp181 (ISIIDTGVDPTH), His247 (HGMHVAGIVAA) and Ser578 (GTSMATPQVAG), consistent with both the order and local consensus patterns of peptidase family S8 (subtilisin family) catalytic triads (Siezen et al., 1991; Siezen \& Leunissen, 1997). Based on sequence identity and similarity, presence of the different domains and the catalytic triad, this novel proteinase was denoted subtilase of Finegoldia magna (SufA).

To confirm the MS/MS identification of SufA, the ORF was in silico digested with trypsin using the MS-Digest program (http://prospector.ucsf.edu/prospector/4.0.8/html/msdigest. $\mathrm{htm})$. When comparing the experimental masses of the 23 de novo peptides with the theoretical masses of the tryptic SufA peptides, 17 of the peptides had experimental values in good agreement with the theoretical masses (Table 1). Eight of these matched peptides were identical at the amino acid level, while the others displayed high homology (40$80 \%$ identity). Several of the other six peptides could also be found in the ORF but with a lower identity or with gaps. Poor fragmentation, inaccuracies due to mass shifts caused by drifts in instrumental parameters, and chemical contaminants could limit the positive identification of peptides (Ma et al., 2003). However, the result from the MS/MS analysis of the protein band above $250 \mathrm{kDa}$ is in good agreement with reports on peptide de novo sequencing of standard proteins, such as albumin (Ma et al., 2003). The location in SufA of the matching 17 peptides is shown in Fig. 3(b).

\section{The gelatinase activity correlates with SufA}

Two constructs of SufA, the pro-enzyme and the mature SufA, were recombinantly expressed in E. coli using the GST fusion system. However, both forms were proteolytically inactive in zymograms. In order to obtain native and active proteins, recombinant SufA was subjected to denaturation with guanidinium chloride or urea followed by refolding in different buffers using dialysis or dilution. The refolding conditions were adopted from protocols 
used for other members of the subtilase family (Hayashi et al., 1994; Nohara et al., 2000; Wang et al., 2003). However, none of the tested methods were successful, and the protein remained proteolytically inactive. This has been reported also for other recombinantly expressed subtilases (Harris et al., 2003; Kluskens et al., 2002).

SufA purified from growth medium and the cell surface of ALB8 was analysed by SDS-PAGE and Western blotting. Both preparations were heterogeneous, with dominating bands at approximately $250 \mathrm{kDa}$ and weaker bands around $130 \mathrm{kDa}$ (Fig. 4a, SDS-PAGE). In Western blots antibodies raised against peptide 3 (anti-EFS12) reacted with a fragment of apparently $115 \mathrm{kDa}$ in both SufA preparations, corresponding to the predicted size of the mature proteinase. The antiserum also reacted with the fragment migrating just below $250 \mathrm{kDa}$ in the SufA preparation purified from papain-solubilized cell-surface proteins (Fig. 4a, anti-EFS12). When antibodies against recombinant pre-SufA were used as the probe, multiple immunoreactive bands were seen in this SufA preparation, suggesting that monomeric and dimeric forms of both the pro-enzyme and the mature SufA are present in the preparation (Fig. 4a, anti-SufA). This antiserum reacted also with the high-molecular-mass band originally used for the identification of SufA. In contrast, in the SufA preparation purified from the growth medium the only band reacting with anti-SufA was the fragment below $250 \mathrm{kDa}$. To demonstrate that SufA associates with the proteolytic activity, immunoprecipitation experiments were performed. As shown in Fig. 4(b), anti-SufA antibodies depleted the SufA preparation from the ALB8 surface of all gelatinase activity, while unspecific antibodies had no such effect. Similarly, no gelatinase activity was found in the SufA preparation from the growth medium following immunoprecipitation with anti-SufA IgG (not shown). These results clearly show that SufA correlates with the enzymic activity in the preparations. Moreover, the data demonstrate that SufA is associated with the bacterial surface, but a fraction of the enzyme is also released into the medium during growth.

\section{SufA degrades and inactivates LL-37 and MIG/ CXCL9}

It has been described that proteinases of significant human pathogens degrade the antibacterial peptide LL-37 (Schmidtchen et al., 2002; Sieprawska-Lupa et al., 2004). To examine if SufA of F. magna also has this activity, LL-37 was incubated with SufA purified from the ALB8 surface, followed by SDS-PAGE. As shown in Fig. 5(a), cleavage of the peptide occurs rapidly (15-30 min), and after incubation for 1-3 h LL-37 was completely degraded. The cleavage of LL-37 was efficiently blocked by PMSF. Similar results were found when LL-37 was incubated with SufA purified from the growth medium of ALB8 (not shown). The human $\alpha$-defensin HNP-1 (human neutrophil peptide 1 ) and the human $\beta$-defensin 3 (hBD-3) were not (a)

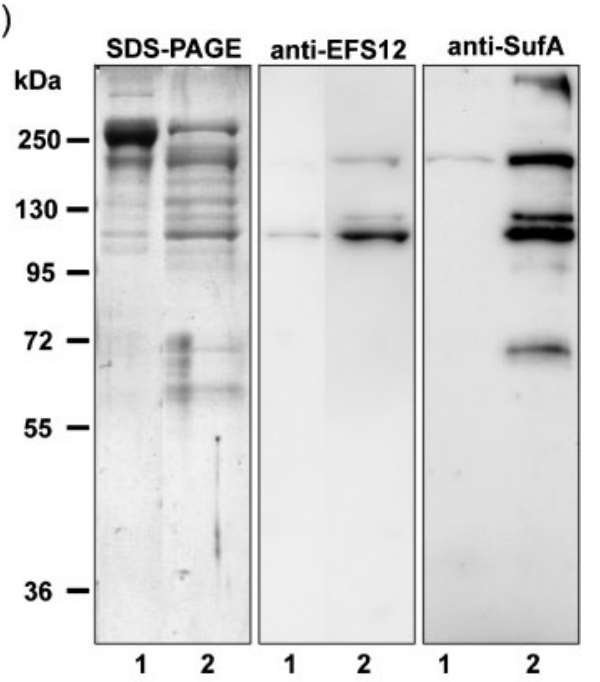

(b)

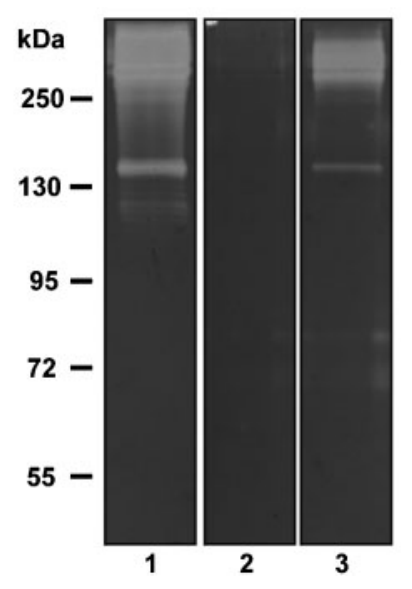

Fig. 4. SufA is present on the surface of $F$. magna but is also released into the growth medium. (a) SufA purified from ALB8 bacteria was run on $8 \%$ SDS-PAGE under reducing conditions. Following transfer to PVDF membranes, anti-EFS12 antibodies or antibodies against intact SufA were used as probes in Western blot experiments. Lanes 1, $2.5 \mu \mathrm{g}$ SufA purified from the growth medium; lanes 2, $2.5 \mu \mathrm{g}$ SufA solubilized from the ALB8 surface and purified. Molecular mass markers are indicated to the left. (b) The active preparation of SufA from the ALB8 surface (see lanes 2 in a) was subjected to immunoprecipitation using antibodies and protein G-Sepharose. Depleted material was analysed on an $8 \%$ polyacrylamide zymogram containing $0.1 \%$ gelatin. Lane 1 , active SufA preparation; lane 2, SufA preparation depleted with anti-SufA lgG; lane 3, SufA preparation depleted with anti-NAT26 lgG.

degraded by SufA, despite incubation for $16 \mathrm{~h}$ (Fig. 5a). However, the ability of hBD-3 to form dimers was inhibited by SufA. Another molecule recently shown to have potent antibacterial activity is the CXC chemokine MIG/CXCL9 (Cole et al., 2001; Egesten et al., 2007). MIG/ CXCL9 was also rapidly degraded, generating fragments of approximately $6-10 \mathrm{kDa}$. No further cleavage of MIG/ 
(a)
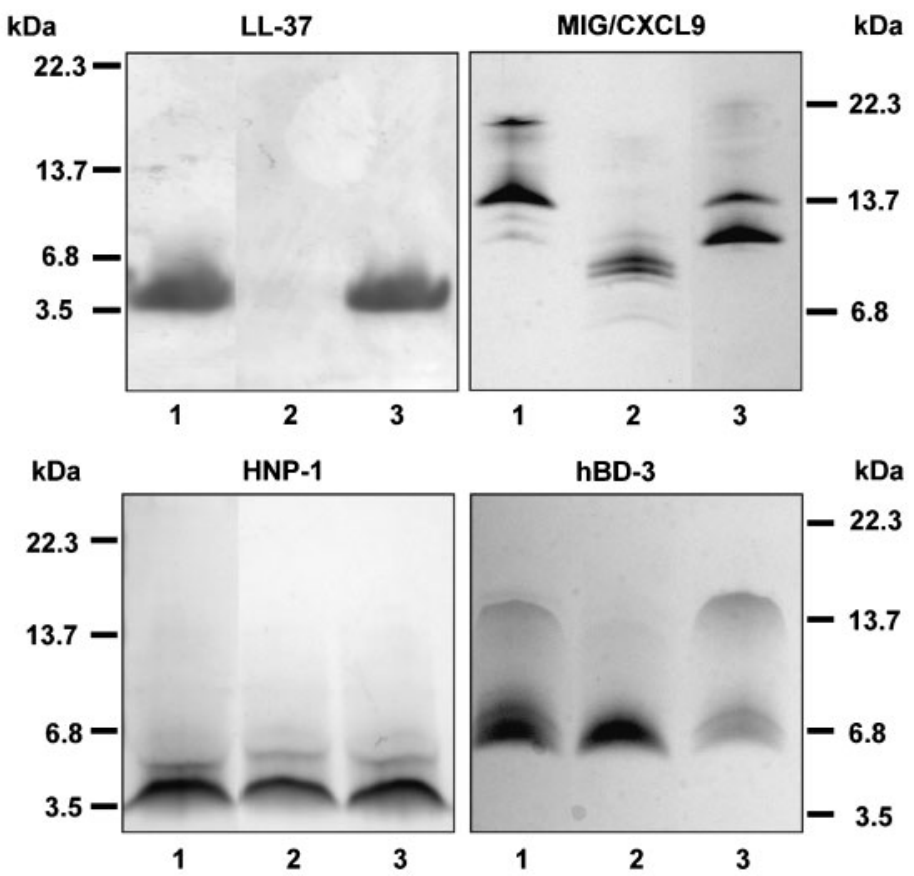

(b)

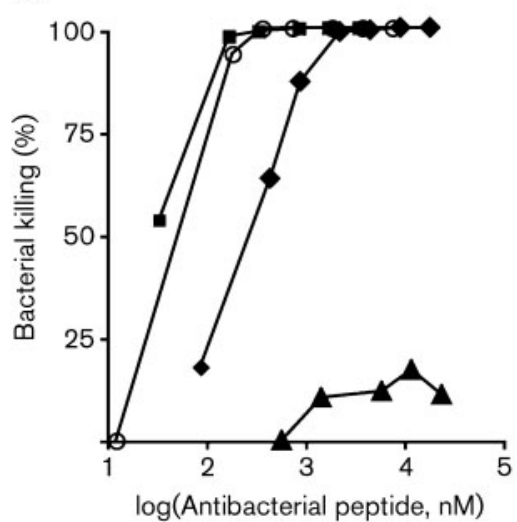

(c)

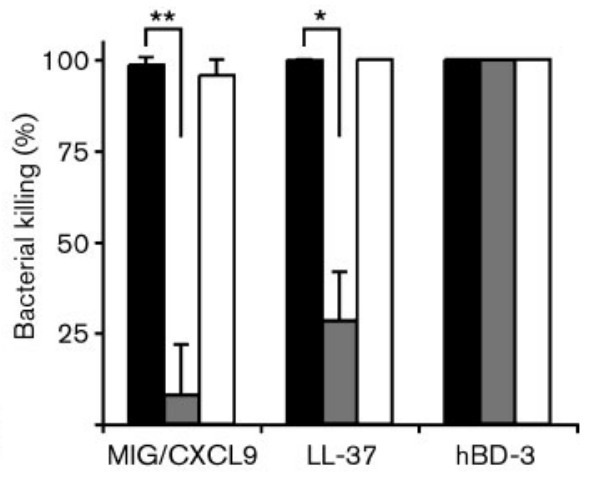

Fig. 5. SufA inactivates $L L-37$ and MIG. (a) The antibacterial peptides LL-37 (4 $\mu \mathrm{g})$, MIG/ CXCL9 $(3 \mu \mathrm{g}), \mathrm{HNP}-1$ (3 $\mu \mathrm{g})$ and hBD-3 $(2 \mu \mathrm{g})$ were incubated with buffer or SufA (250 ng), with or without PMSF (5 mM). Following incubation at $37{ }^{\circ} \mathrm{C}$ for $3 \mathrm{~h}$ (LL-37 and MIG/CXCL9) or $16 \mathrm{~h}$ (HNP-1 and hBD$3)$, the samples were run on $16.5 \%$ TrisTricine gels. Lanes 1, peptide + buffer; lanes 2, peptide +SufA; lanes 3, peptide + SufA + PMSF. Molecular mass markers are indicated to the sides. (b) F. magna strain 505 $\left(2 \times 10^{6}\right.$ c.f.u. $\left.\mathrm{ml}^{-1}\right)$ was incubated with LL-37 $(\boldsymbol{\nabla}), \mathrm{MIG} / \mathrm{CXCL}$ ( $(\boldsymbol{\square}), \mathrm{HNP}-1$ ( $\boldsymbol{\Delta})$ or hBD-3 $(\bigcirc)$ at the indicated concentrations for $1 \mathrm{~h}$ at $37{ }^{\circ} \mathrm{C}$ in buffer under strict anaerobic conditions, and the number of c.f.u. was determined. Experiments were repeated at least three times and representative experiments are shown. (c) LL-37 $(1 \mu \mathrm{g}), \mathrm{MIG} / \mathrm{CXCL} 9(2 \mu \mathrm{g})$ and hBD-3 $(2 \mu \mathrm{g})$ were incubated with buffer, SufA (250 ng) with or without PMSF $(5 \mathrm{mM})$ at $37{ }^{\circ} \mathrm{C}$ for $3 \mathrm{~h}$ (LL-37 and MIG/CXCL9) or $16 \mathrm{~h}$ (hBD-3). Black columns, peptide + buffer; grey columns, peptide+SufA; white columns, peptide+SufA+PMSF. The bactericidal effect of the mixtures was then tested against F. magna strain 505. The bars represent the mean $\pm S D$ of at least three experiments. ${ }^{*}, P<0.05 ;{ }^{* *}, P<0.01$.
CXCL9 occurred as a result of prolonged incubation (Fig. 5a). Futhermore, following immunoprecipitation with anti-SufA IgG, the SufA preparation (see Fig. 4b, lane 2) had no proteolytic activity against LL-37 and MIG/ CXCL9 (data not shown), while unspecific antibodies did not block the cleavage of the peptides.

Next, the bactericidal activity of the various peptides on $F$. magna strain 505 was examined. This strain carries the sufA gene, but at stationary phase low amounts of SufA are secreted (Fig. 1a). In these experiments the bacteria were washed and resuspended in buffer prior to the addition of the peptides. All peptides except HNP-1 dose-dependently killed the bacteria (Fig. 5b). The peptides were then preincubated with SufA followed by the testing of the antibacterial effect on strain 505. At a concentration required for $100 \%$ killing, cleavage of LL-37 and MIG/ CXCL9 by SufA significantly reduced the antibacterial activity of the peptides (Fig. 5c). When SufA was blocked with PMSF, both LL-37 and MIG/CXCL9 regained their activity (Fig. 5c). The interference of SufA with hBD-3 dimerization (Fig. 5a) had no effect on the antibacterial activity of this peptide (Fig. 5c), and PMSF alone had no bactericidal effect on strain 505 (data not shown). In summary, the data demonstrate that members of the defensin family are resistant to SufA proteolysis, whereas the antibacterial peptides LL-37 and MIG/CXCL9 are cleaved and inactivated, resulting in enhanced survival of $F$. magna.

\section{Distribution of the sufA gene in strains of F. magna}

A collection of $34 \mathrm{~F}$. magna strains isolated from clinical specimens was analysed by PCR for the presence of the sufA gene. The gene was identified using forward primers hybridizing with the signal sequence or the histidine site, 
together with a reverse primer hybridizing with the serine active site. PCR products of the correct sizes were detected in 27 strains using the signal sequence forward primer, and in 33 strains using the histidine forward primer. The expression of SufA was then examined by growing the strains to stationary phase and analysing the growth media in Western blots or slot blots using the peptide antibody EFS12. Twenty-four strains were found positive for SufA expression. In fact only one strain was negative at both the gene and protein level. In Western blot analysis of growth media from the strains shown in Fig. 1(a), anti-SufA antibodies reacted with a band below $250 \mathrm{kDa}$ in all strains. Apart from ELTI and 23.75, an immunoreactive band around $130 \mathrm{kDa}$ was also detected in all strains (data not shown). Moreover, sequencing of the $\mathrm{NH}_{2}$-terminal amino acid residues 41-322 (see Fig. 3a) in four additional strains, including L3410, 23.75 and 505 shown in Fig. 1(a), revealed a high degree of homology (more than $80 \%$ identity). Of course it can not be excluded that, in addition to the expression of SufA homologues, the various strains in Fig. 1(a) also express other gelatinases, which could contribute to the banding pattern. Furthermore, the enzymic activity in zymograms of variants of SufA could also differ. Taken together, the data demonstrate that wellconserved homologues of SufA are present in almost all $F$. magna isolates.

\section{DISCUSSION}

Gelatinase and collagenase activities have been described previously in F. magna (Harrington, 1996; Krepel et al., 1992; Steffen \& Hentges, 1981), but the proteinase(s) responsible have not been isolated and characterized. Here we show that this anaerobic bacterium expresses a serine proteinase, denoted SufA, which is associated with the bacterial surface, but also released in substantial amounts into the growth medium. SufA is homologous to members of a family of subtilisin-like serine proteinases, also referred to as subtilases (Rawlings \& Barrett, 1994; Siezen et al., 1991; Siezen \& Leunissen, 1997). Most subtilases of Grampositive bacteria are secreted, although some have classical cell-wall anchoring domains (S-layer homology domains or LPXTG motifs). No such motifs were, however, found in the SufA sequence, suggesting a non-covalent association with the F. magna surface.

In general, subtilisins are produced as pro-enzymes and undergo autocatalytic maturation, where the pro-domain is cleaved off. Following cleavage, the propeptide generally remains non-covalently bound to the catalytic region of the subtilase, where it can act as an inhibitor (Shinde \& Inouye, $1995 a$, b). Removal of the propeptide is also an autocatalytic process, resulting in a fully active enzyme. In some cases pro-domains have been shown to function as intramolecular chaperones involved in correct folding of the protein (Takagi \& Takahashi, 2003; Zhu et al., 1989). Sequence similarity suggests that SufA also has a prodomain, which is further supported by the fact that none of the identified de novo peptides were found $\mathrm{NH}_{2}$-terminal of amino acid residue 195 in the SufA sequence (see Fig. 3). When expressed in E. coli, SufA showed no proteolytic activity. In order to adopt their native bioactive structure, it has been reported that E. coli-produced subtilisin-like proteinases require refolding (Matsubara et al., 1994; Moser et al., 1994; Nohara et al., 2000). However, despite testing several refolding strategies, both forms of recombinant SufA remained enzymically inactive. The addition of $F$. magna cell extract or trace amounts of purified SufA also failed to restore the activity of the recombinant proteinases (data not shown). After proteolytic removal of the GST-tag, 18 amino acids from GST remain in the $\mathrm{NH}_{2}-$ terminus of E. coli-expressed SufA. Hypothetically, these residues could interfere with the refolding, especially if the pro-domain is required for renaturation. As an alternative approach, subcloning of SufA into an expression plasmid yielding a C-terminal hexahistidine-tagged protein was attempted, but this experimental procedure was not successful.

Sequencing of SufA was based on MS/MS peptides derived from a protein migrating with an apparent molecular mass of $>250 \mathrm{kDa}$ and showing the highest proteolytic activity in zymography (see Fig. 2b). This band most likely corresponds to a dimer/multimer of SufA as judged by Western blot analyses, where the band reacts with antibodies raised against recombinant SufA with an apparent molecular mass of $130 \mathrm{kDa}$ (see Fig. 4a). In SufA preparations from ALB8 bacteria, immunoreactive fragments compatible with the size of monomers and dimers of both the propeptide and the mature proteinase were seen. However, at the size for monomeric SufA the proteolytic activity was considerably lower, suggesting that dimer formation is required for full enzymic activity.

Antimicrobial peptides (AMPs) play a significant role in the clearance of potentially pathogenic microbes at physical barriers. Cathelicidins and defensins constitute the major AMPs (Bals \& Wilson, 2003; Ganz, 2003), but other molecules such as chemokines also possess bactericidal activity (Cole et al., 2001; Egesten et al., 2007). During inflammation an upregulated synthesis of AMPs by epithelial cells and degranulation from neutrophils result in elevated concentrations of these peptides. Here we find that SufA rapidly cleaves and inactivates the human cathelicidin LL-37 and the chemokine MIG/CXCL9, and as a consequence growth of $F$. magna is significantly enhanced. Such proteolytic inactivation of AMPs has been reported for other bacterial proteinases (Hidalgo-Grass et al., 2006; Schmidtchen et al., 2002; Sieprawska-Lupa et al., 2004) and could thus represent a common strategy to promote bacterial survival and colonization of epithelial surfaces. F. magna is associated with soft tissue infections (Murdoch, 1998) and the bacterium is also isolated from patients with deep wound infections and chronic wounds (Hansson et al., 1995; Stephens et al., 2003). The inactivation of LL-37 and MIG/CXCL9 by SufA may contribute to the potential pathogenicity of $F$. magna by 
promoting survival and spread of this commensal to sites where it is not present under normal conditions.

Among the $\beta$-defensins hBD-3 is a broad-spectrum antibacterial peptide mainly expressed in skin and tonsils (Harder et al., 2001). Only a small amount of hBD-3 is found in normal skin, but following wounding the epidermal expression of hBD-3 is greatly increased by activation of the epidermal growth factor receptor (Sörensen et al., 2006). In our in vitro assay F. magna was efficiently killed by hBD-3, but, in contrast to LL-37 and MIG/CXCL9, hBD-3 was not degraded by SufA. Interestingly, this was also the case with the $\alpha$-defensin HNP-1, suggesting that cysteine-rich peptides are protected from SufA proteolysis. The observation that serine-threonine proteinases are unable to degrade the folded form of hBD-3 (Dhople et al., 2006) supports this assumption. By contrast, LL-37 is a linear $\alpha$-helical peptide without cysteines (Bals \& Wilson, 2003), and in MIG/CXCL9 the antibacterial activity has been localized to the C-terminal region, which has a predicted $\alpha$ helical structure (Egesten et al., 2007). Thus, it seems likely that $\alpha$-helical peptides in general are susceptible for proteolysis by SufA. On the other hand, SufA interfered with the ability of hBD-3 to form dimers, but this property had no impact on the bactericidal activity towards F. magna. Whether other biological functions of hBD-3, such as chemoattraction (Dhople et al., 2006), are affected by SufA, remains to be investigated.

To our knowledge this study represents the first report on a subtilase produced by anaerobic Gram-positive cocci. In this group of bacteria $F$. magna is the most commonly isolated organism from clinical specimens, indicating a relatively higher pathogenic potential for this bacterium compared to other anaerobic Gram-positive cocci of the normal flora. At mucosal surfaces growth of $F$. magna will be influenced by constitutively produced antibacterial peptides, such as hBD3. On the other hand, expression of SufA leads to the inactivation of other antibacterial peptides, which should favour F. magna colonization. The large majority of examined F. magna isolates were found to carry the sufA gene and most of these isolates also expressed the protein in vitro. Taken together, the data suggest an important role for SufA in the colonization, survival and spread of a commensal and potential pathogen.

\section{ACKNOWLEDGEMENTS}

We acknowledge the help with the protein analysis from the SCIBLU Proteomics Resource Centre at Lund University and the Wallenberg Stiftelse (KAW). We thank Elisabeth Holst for helpful assistance. This work was supported by the Swedish Research Council (project 7480), the Foundations of Crafoord, Kock, Bergvall and Österlund, the Royal Physiographic Society and Hansa Medical AB.

\section{REFERENCES}

Bals, R. \& Wilson, J. M. (2003). Cathelicidins - a family of multifunctional antimicrobial peptides. Cell Mol Life Sci 60, 711-720.
Bendtsen, J. D., Nielsen, H., von Heijne, G. \& Brunak, S. (2004). Improved prediction of signal peptides: SignalP 3.0. J Mol Biol 340, 783-795.

Björck, L. (1988). Protein L. A novel bacterial cell wall protein with affinity for Ig L chains. J Immunol 140, 1194-1197.

Bowler, P. G. \& Davies, B. J. (1999). The microbiology of infected and noninfected leg ulcers. Int J Dermatol 38, 573-578.

Chen, C. C. \& Cleary, P. P. (1990). Complete nucleotide sequence of the streptococcal C5a peptidase gene of Streptococcus pyogenes. J Biol Chem 265, 3161-3167.

Choih, S., Smith, Q. T. \& Schachtele, C. F. (1979). Modification of human parotid saliva proteins by oral Streptococcus sanguis. J Dent Res 58, 516-524.

Cole, A. M., Ganz, T., Liese, A. M., Burdick, M. D., Liu, L. \& Strieter, R. M. (2001). Cutting edge: IFN-inducible ELR-CXC chemokines display defensin-like antimicrobial activity. J Immunol 167, 623-627.

de Château, M. \& Björck, L. (1994). Protein PAB, a mosaic albuminbinding bacterial protein representing the first contemporary example of module shuffling. J Biol Chem 269, 12147-12151.

Dhople, V., Krukemeyer, A. \& Ramamoorthy, A. (2006). The human beta-defensin-3, an antibacterial peptide with multiple biological functions. Biochim Biophys Acta 1758, 1499-1512.

Egesten, A., Eliasson, M., Johansson, H. M., Olin, A. I., Mörgelin, M., Mueller, A., Pease, J. E., Frick, I. M. \& Björck, L. (2007). The CXC chemokine MIG/CXCL9 is important in innate immunity against Streptococcus pyogenes. J Infect Dis 195, 684-693.

Frick, I. M., Åkesson, P., Herwald, H., Mörgelin, M., Malmsten, M., Nägler, D. K. \& Björck, L. (2006). The contact system - a novel branch of innate immunity generating antibacterial peptides. EMBO J 25, 5569-5578.

Ganz, T. (2003). Defensins: antimicrobial peptides of innate immunity. Nat Rev Immunol 3, 710-720.

Goto, T., Todo, K., Miyamoto, K. \& Akimoto, S. (2003). Bacterial artificial chromosome library of Finegoldia magna ATCC 29328 for genetic mapping and comparative genomics. Microbiol Immunol 47, 1005-1016.

Hansson, C., Hoborn, J., Moller, A. \& Swanbeck, G. (1995). The microbial flora in venous leg ulcers without clinical signs of infection. Repeated culture using a validated standardised microbiological technique. Acta Derm Venereol 75, 24-30.

Harder, J., Bartels, J., Christophers, E. \& Schröder, J. M. (2001). Isolation and characterization of human beta-defensin-3, a novel human inducible peptide antibiotic. J Biol Chem 276, 5707-5713.

Harrington, D. J. (1996). Bacterial collagenases and collagendegrading enzymes and their potential role in human disease. Infect Immun 64, 1885-1891.

Harris, T. O., Shelver, D. W., Bohnsack, J. F. \& Rubens, C. E. (2003). A novel streptococcal surface protease promotes virulence, resistance to opsonophagocytosis, and cleavage of human fibrinogen. J Clin Invest 111, 61-70.

Hayashi, T., Matsubara, M., Nohara, D., Kojima, S., Miura, K. \& Sakai, T. (1994). Renaturation of the mature subtilisin $\mathrm{BPN}^{\prime}$ immobilized on agarose beads. FEBS Lett 350, 109-112.

Herwald, H., Collin, M., Müller-Esterl, W. \& Björck, L. (1996). Streptococcal cysteine proteinase releases kinins: a virulence mechanism. J Exp Med 184, 665-673.

Hidalgo-Grass, C., Mishalian, I., Dan-Goor, M., Belotserkovsky, I., Eran, Y., Nizet, V., Peled, A. \& Hanski, E. (2006). A streptococcal protease that degrades CXC chemokines and impairs bacterial clearance from infected tissues. EMBO J 25, 4628-4637. 
Imamura, T., Potempa, J. \& Travis, J. (2004). Activation of the kallikrein-kinin system and release of new kinins through alternative cleavage of kininogens by microbial and human cell proteinases. Biol Chem 385, 989-996.

Imamura, T., Tanase, S., Szmyd, G., Kozik, A., Travis, J. \& Potempa, J. (2005). Induction of vascular leakage through release of bradykinin and a novel kinin by cysteine proteinases from Staphylococcus aureus. J Exp Med 201, 1669-1676.

Kluskens, L. D., Voorhorst, W. G., Siezen, R. J., Schwerdtfeger, R. M., Antranikian, G., van der Oost, J. \& de Vos, W. M. (2002). Molecular characterization of fervidolysin, a subtilisin-like serine protease from the thermophilic bacterium Fervidobacterium pennivorans. Extremophiles 6, 185-194.

Knoth, K., Roberds, S., Poteet, C. \& Tamkun, M. (1988). Highly degenerate, inosine-containing primers specifically amplify rare cDNA using the polymerase chain reaction. Nucleic Acids Res 16, 10932.

Krepel, C. J., Gohr, C. M., Walker, A. P., Farmer, S. G. \& Edmiston, C. E. (1992). Enzymatically active Peptostreptococcus magnus: association with site of infection. J Clin Microbiol 30, 2330-2334.

Laemmli, U. K. (1970). Cleavage of structural proteins during the assembly of the head of bacteriophage T4. Nature 227, 680-685.

Lardelli, M. (2002). Nonspecific, nested suppression PCR method for isolation of unknown flanking DNA ("cold-start method"). Methods Mol Biol 192, 285-291.

Liotta, L. A. \& Stetler-Stevenson, W. G. (1990). Metalloproteinases and cancer invasion. Semin Cancer Biol 1, 99-106.

Lo, C. S. \& Hughes, C. V. (1996). Identification and characterization of a protease from Streptococcus oralis C104. Oral Microbiol Immunol 11, 181-187.

Ma, B., Zhang, K., Hendrie, C., Liang, C., Li, M., Doherty-Kirby, A. \& Lajoie, G. (2003). PEAKS: powerful software for peptide de novo sequencing by tandem mass spectrometry. Rapid Commun Mass Spectrom 17, 2337-2342.

Matsubara, M., Kurimoto, E., Kojima, S., Miura, K. \& Sakai, T. (1994). Achievement of renaturation of subtilisin $\mathrm{BPN}^{\prime}$ by a novel procedure using organic salts and a digestible mutant of Streptomyces subtilisin inhibitor. FEBS Lett 342, 193-196.

Moser, M., Menz, G., Blaser, K. \& Crameri, R. (1994). Recombinant expression and antigenic properties of a 32-kilodalton extracellular alkaline protease, representing a possible virulence factor from Aspergillus fumigatus. Infect Immun 62, 936-942.

Murdoch, D. A. (1998). Gram-positive anaerobic cocci. Clin Microbiol Rev 11, 81-120.

Nakamura, Y., Gojobori, T. \& Ikemura, T. (2000). Codon usage tabulated from international DNA sequence databases: status for the year 2000. Nucleic Acids Res 28, 292.

Nohara, D., Senga, Y., Matsubara, M. \& Sakai, T. (2000). Media selection for refolding of thermolysin by use of immobilized preparation. J Biosci Bioeng 89, 188-192.

Pagni, M., loannidis, V., Cerutti, L., Zahn-Zabal, M., Jongeneel, C. V. \& Falquet, L. (2004). MyHits: a new interactive resource for protein annotation and domain identification. Nucleic Acids Res 32, W332-W335.

Plaut, A. G., Genco, R. J. \& Tomasi, T. B., Jr (1974). Isolation of an enzyme from Streptococcus sanguis which specifically cleaves IgA. J Immunol 113, 589-591.

Potempa, J., Banbula, A. \& Travis, J. (2000). Role of bacterial proteinases in matrix destruction and modulation of host responses. Periodontol 2000 24, 153-192.

Rasmussen, M. \& Björck, L. (2002). Proteolysis and its regulation at the surface of Streptococcus pyogenes. Mol Microbiol 43, 537-544.
Rawlings, N. D. \& Barrett, A. J. (1994). Families of serine peptidases. Methods Enzymol 244, 19-61.

Schägger, H. \& von Jagow, G. (1987). Tricine-sodium dodecyl sulfate-polyacrylamide gel electrophoresis for the separation of proteins in the range from 1 to $100 \mathrm{kDa}$. Anal Biochem 166, 368-379.

Schmidtchen, A., Frick, I. M., Andersson, E., Tapper, H. \& Björck, L. (2002). Proteinases of common pathogenic bacteria degrade and inactivate the antibacterial peptide LL-37. Mol Microbiol 46, 157-168.

Scott, C. F., Whitaker, E. J., Hammond, B. F. \& Colman, R. W. (1993). Purification and characterization of a potent $70-\mathrm{kDa}$ thiol lysylproteinase (Lys-gingivain) from Porphyromonas gingivalis that cleaves kininogens and fibrinogen. J Biol Chem 268, 7935-7942.

Shinde, U. \& Inouye, M. (1995a). Folding pathway mediated by an intramolecular chaperone: characterization of the structural changes in pro-subtilisin E coincident with autoprocessing. J Mol Biol 252, 25-30.

Shinde, U. \& Inouye, M. (1995b). Folding mediated by an intramolecular chaperone: autoprocessing pathway of the precursor resolved via a substrate assisted catalysis mechanism. J Mol Biol 247, 390-395.

Sieprawska-Lupa, M., Mydel, P., Krawczyk, K., Wójcik, K., Puklo, M., Lupa, B., Suder, P., Silberring, J., Reed, M. \& other authors (2004). Degradation of human antimicrobial peptide LL-37 by Staphylococcus aureus-derived proteinases. Antimicrob Agents Chemother 48, 4673-4679.

Siezen, R. J. \& Leunissen, J. A. (1997). Subtilases: the superfamily of subtilisin-like serine proteases. Protein Sci 6, 501-523.

Siezen, R. J., de Vos, W. M., Leunissen, J. A. \& Dijkstra, B. W. (1991). Homology modelling and protein engineering strategy of subtilases, the family of subtilisin-like serine proteinases. Protein Eng 4, 719-737.

Sörensen, O. E., Thapa, D. R., Roupe, K. M., Valore, E. V., Sjöbring, U., Roberts, A. A., Schmidtchen, A. \& Ganz, T. (2006). Injury-induced innate immune response in human skin mediated by transactivation of the epidermal growth factor receptor. J Clin Invest 116, 1878-1885.

Steffen, E. K. \& Hentges, D. J. (1981). Hydrolytic enzymes of anaerobic bacteria isolated from human infections. J Clin Microbiol 14, 153-156.

Stephens, P., Wall, I. B., Wilson, M. J., Hill, K. E., Davies, C. E., Hill, C. M., Harding, K. G. \& Thomas, D. W. (2003). Anaerobic cocci populating the deep tissues of chronic wounds impair cellular wound healing responses in vitro. Br J Dermatol 148, 456-466.

Takagi, H. \& Takahashi, M. (2003). A new approach for alteration of protease functions: pro-sequence engineering. Appl Microbiol Biotechnol 63, 1-9.

Thwaite, J. E., Hibbs, S., Titball, R. W. \& Atkins, T. P. (2006). Proteolytic degradation of human antimicrobial peptide LL-37 by Bacillus anthracis may contribute to virulence. Antimicrob Agents Chemother 50, 2316-2322.

Travis, J., Potempa, J. \& Maeda, H. (1995). Are bacterial proteinases pathogenic factors? Trends Microbiol 3, 405-407.

von Pawel-Rammingen, U. \& Björck, L. (2003). IdeS and SpeB: immunoglobulin-degrading cysteine proteinases of Streptococcus pyogenes. Curr Opin Microbiol 6, 50-55.

Wang, J. J., Swaisgood, H. E. \& Shih, J. C. (2003). Bioimmobilization of keratinase using Bacillus subtilis and Escherichia coli systems. Biotechnol Bioeng 81, 421-429.

Zhu, X. L., Ohta, Y., Jordan, F. \& Inouye, M. (1989). Pro-sequence of subtilisin can guide the refolding of denatured subtilisin in an intermolecular process. Nature 339, 483-484.

Edited by: K. E. Weaver 